\title{
Temporal profiling of the transcriptional basis for the development of corticosteroid-induced insulin resistance in rat muscle
}

\author{
Richard R Almon ${ }^{1,2}$, Debra C DuBois ${ }^{1,2}$, Jin $\mathrm{Y}$ Jin $^{2}$ and \\ William J Jusko ${ }^{2}$ \\ ${ }^{1}$ Department of Biological Sciences, State University of New York at Buffalo, Buffalo, NY 14260, USA \\ ${ }^{2}$ Department of Pharmaceutical Sciences, State University of New York at Buffalo, Buffalo, NY 14260, USA \\ (Requests for offprints should be addressed to R R Almon; Email: almon@eng.buffalo.edu)
}

\begin{abstract}
Elevated systemic levels of glucocorticoids are causally related to peripheral insulin resistance. The pharmacological use of synthetic glucocorticoids (corticosteroids) often results in insulin resistance/type II diabetes. Skeletal muscle is responsible for close to $80 \%$ of the insulininduced systemic disposal of glucose and is a major target for glucocorticoid-induced insulin resistance. We used Affymetrix gene chips to profile the dynamic changes in mRNA expression in rat skeletal muscle in response to a single bolus dose of the synthetic glucocorticoid methylprednisolone. Temporal expression profiles (analyzed on individual chips) were obtained from tissues of 48 drugtreated animals encompassing 16 time points over $72 \mathrm{~h}$ following drug administration along with four vehicletreated controls. Data mining identified 653 regulated probe sets out of 8799 present on the chip. Of these 653 probe sets we identified 29, which represented 22 gene
\end{abstract}

transcripts, that were associated with the development of insulin resistance. These 29 probe sets were regulated in three fundamental temporal patterns. 16 probe sets coding for 12 different genes had a profile of enhanced expression. 10 probe sets coding for eight different genes showed decreased expression and three probe sets coding for two genes showed biphasic temporal signatures. These transcripts were grouped into four general functional categories: signal transduction, transcription regulation, carbohydrate/fat metabolism, and regulation of blood flow to the muscle. The results demonstrate the polygenic nature of transcriptional changes associated with insulin resistance that can provide a temporal scaffolding for translational and post-translational data as they become available.

Journal of Endocrinology (2005) 184, 219-232

\section{Introduction}

A major function of the hypothalmic/pituitary/adrenal axis is control of blood glucose levels through the regulation of systemic gluconeogenesis. Aspects of this broad systemic function of glucocorticoids include increased gluconeogenesis in the liver and kidney, net muscleprotein breakdown to provide gluconeogenic substrates, insulin resistance of peripheral tissues including skeletal muscle, and lipid mobilization.

Glucocorticoids also suppress inflammatory/immune responses, and synthetic glucocorticoids (corticosteroids) are widely used therapeutically for this purpose (Schimmer \& Parker 1996, Baxter 2000). The pathologies for which anti-inflammatory or immune-suppressing interventions by corticosteroids are used are numerous and include diverse types of organ transplantation. When corticosteroids are used pharmacologically aspects relating to their systemic glucose regulation are also amplified, resulting in numerous adverse effects (Frauman 1996, Bialis \&
Routledge 1998, Reynolds \& Walker 2003, Tomono et al. 2002).

Corticosteroids cause insulin resistance, which occurs in conjunction with increased gluconeogenesis by the liver and kidney, and results in chronic hyperglycemia (Beck-Nielsen et al. 2002, Tomono et al. 2002, Reynolds \& Walker 2003). Skeletal muscle is responsible for close to $80 \%$ of the insulin-directed glucose disposal by peripheral tissues. Therefore, muscle to a great extent is responsible for reduced glucose disposal and consequent hyperglycemia caused by peripheral insulin resistance (Koistinen $\&$ Zierath 2002). In skeletal muscle insulin directs glucose uptake through the GLUT4 transporter, and facilitates glucose disposal by both glycogen synthesis and glycolysis. Insulin also reduces fat utilization through $\beta$-oxidation in muscle. In addition, by way of its combined effects on both muscle and muscle vasculature, it increases blood flow through the musculature, facilitating glucose uptake (Rakugi et al. 2002). These effects of insulin in facilitating glucose disposal involve actions at the transcriptional, 
translational, and post-translational levels (Sugden \& Holness 2002, Zierath \& Wallberg-Henriksson 2002).

Unlike insulin, which has many of its effects through post-translational kinase cascades, glucocorticoids have most of their effects by altering transcription of specific genes. These transcriptional effects take two fundamental forms. Many regulated genes contain glucocorticoidresponsive elements in their regulatory sequences and their transcription is influenced directly. However, there are a large number of genes whose transcription is altered indirectly by glucocorticoids. In these cases glucocorticoids alter the expression or function of other transcription factors, which in turn alter the transcription of other genes (Sun et al. 1998a, 1998b, 1999, Almon et al. 2002, Rosmond 2003).

In the present study we used the rat model for corticosteroid-induced insulin resistance and employed Affymetrix gene arrays to profile the time course of changes in gene expression in skeletal muscle of adrenalectomized (ADX) male rats in response to a single bolus dose of the synthetic corticosteroid, methylprednisolone (MPL). ADX animals were used to eliminate circadian oscillation in corticosteroid-responsive genes, which facilitated data mining. The objective was to identify those changes in transcription induced by corticosteroids, which, if perpetuated by repeated dosing, would manifest as chronic insulin resistance. Using a filtering approach to eliminate probe sets that were not regulated we identified 653 probe sets out of 8799 with a high probability of being regulated (Almon et al. 2004). Of the 653 probe sets, 29 (representing 22 gene transcripts) directly related to insulin resistance. These probe sets can be divided into four functional categories. The first is signal transduction. The second is transcription regulation. The third is related to carbohydrate and fat metabolism. The fourth group is expressed either by the muscle, by the muscle vasculature, or both and influences the relationship between the muscle and blood flow. Together these results provide a broad temporal tableau of the polygenic nature of insulin resistance caused by corticosteroids.

\section{Materials and Methods}

\section{Experimental design}

Muscle samples (gastrocnemius) were obtained from a previously performed animal study in our laboratory (Sun et al. 1998a, 1999). All procedures involving experimental animals adhered to the Principles of Laboratory Animal Care (National Institutes of Health, 1985) and were reviewed by our institution's animal care and use committee. Male ADX Wistar rats (Rattus rattus) weighing 225-250 g were obtained from Harlan Sprague-Dawley (Indianapolis, IN). Animals were allowed free access to rat chow (RMH 1000; Agway, Harlan Teklad, Madison, WI, USA) and $0 \cdot 9 \% \mathrm{NaCl}$ drinking water. They were housed in a room with a $12 \mathrm{~h}$ light $/ 12 \mathrm{~h}$ dark cycle and a constant temperature of $22{ }^{\circ} \mathrm{C}$, and were allowed to acclimatize to this environment for at least 1 week. One day prior to the study, all rats were subjected to right external jugular-vein cannulation under light ether anesthesia. Cannula patency was maintained with sterile $0.9 \% \mathrm{NaCl}$ solution. Four animals were designated as controls (i.e. 0 time samples) and were cannulated but received vehicle only. All remaining animals received a single $50 \mathrm{mg} / \mathrm{kg}$ dose of methylprednisolone sodium succinate (Pharmacia-Upjohn Company, Kalamazoo, MI, USA) via the cannula over $30 \mathrm{~s}$. Rats (three per time point) were killed by exsanguination under anesthesia at $0 \cdot 25,0 \cdot 5,0 \cdot 75,1,2,4,5$, $5 \cdot 5,6,7,8,12,18,30,48$, and $72 \mathrm{~h}$ after dosing. The sampling time points were selected based on previous studies describing glucocorticoid receptor (GR) dynamics and enzyme induction in skeletal muscle. In addition, four cannulated vehicle-treated rats were killed as controls (data represented as time 0). Gastrocnemius muscles were rapidly excised, flash-frozen in liquid nitrogen, and stored at $-80{ }^{\circ} \mathrm{C}$. Frozen muscle tissues were ground into powder using liquid-nitrogen-chilled mortars and pestles. Great care was taken to maintain tissues at temperatures of $-80{ }^{\circ} \mathrm{C}$ or below at all times prior to RNA processing in order to prevent RNA degradation. In a companion study of six animals, blood samples were taken serially from the cannula into a heparinized syringe at $0 \cdot 5,1,2,4,5,6,8$, $10,12,24,36,48$, and $72 \mathrm{~h}$.

\section{Assays}

Plasma MPL concentrations were measured by a normalphase high-performance liquid chromatography method with a quantitation limit of $10 \mathrm{ng} / \mathrm{ml}$ as described previously (Sun et al. 1998a, 1999). A modified enzymatic assay kit (Sigma Diagnostics, St. Louis, MO, USA) was used to determine plasma glucose according to the manufacturer's instructions. Plasma insulin concentrations were measured by a rat-specific enzyme-linked immunosorbent assay kit (1-2-3 Rat Insulin ELISA; ALPCO Diagnostics, Windham, NH, USA). The analysis was performed in duplicate according to the manufacturer's instructions and controlled by Mammalian/Rat Insulin Two-Level Control (ALPCO Diagnostics). The limit of quantitation for this assay was $0 \cdot 07 \mathrm{ng} / \mathrm{ml}$.

\section{Microarrays}

Muscle powder $(100 \mathrm{mg}$ ) from each individual animal was added to $1 \mathrm{ml}$ of pre-chilled Trizol reagent (Invitrogen, Carlsbad, CA, USA). Total RNA extractions were carried out according to the manufacturer's directions. Extracted RNAs were further purified by passage through RNeasy mini-columns (Qiagen, Valencia, CA, USA) according to the manufacturer's protocols for RNA clean-up. Final RNA preparations were resuspended in nuclease-free water and stored at $-80^{\circ} \mathrm{C}$. RNAs were quantified 
spectrophotometrically and purity and integrity assessed by agarose gel electrophoresis. All RNA samples exhibited $260 / 280$ ratios between $1 \cdot 8$ and $2 \cdot 0$, and all exhibited discrete ribosomal bands on agarose gels, indicating a lack of substantial sample degradation. We have found that tissues maintained carefully at ultra-low temperatures produce high-quality RNA, after even 10 years of storage.

Isolated RNA from each individual muscle was used to prepare target according to the manufacturer's protocols. The biotinylated cRNAs were hybridized to 51 individual Affymetrix GeneChips ${ }^{\oplus}$ Rat Genome U34A (Affymetrix, Santa Clara, CA, USA), which contained 8799 probe sets. Unlike the cDNA arrays used in a previous study (Almon et al. 2002), the high reproducibility of in situ synthesis of oligonucleotide chips allows accurate comparison of signals generated by samples hybridized to separate arrays. This entire data-set has been submitted to the NCBI Gene Expression Omnibus database (GSE490) and is also available online at http://pepr.cnmcresearch.org (Almon et al. 2004).

\section{Array analysis}

The approach to data mining was developed based on our use of gene arrays as a technique for high-throughput data collection within the context of a rigidly controlled time-series paradigm. The Affymetrix oligonucleotide microarrays use sequence information and photolithograpy-directed combinatorial chemical synthesis to develop probe sets for the genes of interest. Each probe set consists of a series of short oligonucleotide sequences and an identical partner sequence, except for a single base mismatch in the center. The mismatch sequence provides a unique background for each sequence in the series. The Affymetrix arrays used have the advantage of having multiple measurements per gene (11 probe pairs or more per transcript). However, this same redundancy leads to many different interpretations of probe sets to determine a signal for each gene (probe set algorithms), and controversy regarding the sensitivity and specificity of resulting signals exists, as do appropriate normalization methods (Tumor Analysis Best Practices Working Group 2004). We have used the Affymetrix MAS5.0 algorithm, and this places a relatively high penalty for mismatch hybridization, favoring specificity over sensitivity (Seo et al. 2004). In this first step, a 'call' of Present (P), Absent (A), or Marginal (M) was determined for each probe set on each chip based on the comparison of the matched and mismatched pairs for the gene sequence. The results were normalized for each chip using a distribution of all genes around the 50th percentile. The results from the first step were entered into the program GeneSpring 6.2 (Silicon Genetics, Redwood City, CA, USA). This robust software provides a number of tools for visualization and analysis of time-series data. One such tool for both hierarchical clustering and visualization is the gene-tree approach described by Eisen et al.
(1998), as modified by the GeneSpring software. This algorithm can be used to construct a dendrogram of genes with similar patterns.

A negative aspect of this tool, and most time-series data-mining tools, is the assumption that the points in the time series are equally spaced. However, to design our 72-h time series in this manner would have ignored the richness of biological information during the early period following dosing of the drug. Notwithstanding this drawback, gene trees provide an excellent method of visualizing the data-set. In order for this and other tools to be used it was also necessary to transform the data so that the values for all probe sets were within the same range. To accomplish this, values for each individual probe set on each chip were expressed as a ratio of the mean of the four control values for that gene, which we refer to as normalized intensity. Thus the average of each probe set has a value of 1 at 0 time and either increases, decreases, or remains unchanged relative to controls over the time series. A series of filters was developed and applied to this data-set, which included filtering for expression of the probe set in the tissue, filtering for regulation of the probe set by the drug, and quality-control filtering. Genes selected as potentially regulated by drug using these filtering techniques were then subjected to a one-way ANOVA with a post-hoc Tukey's test $(P<0 \cdot 05)$. A detailed discussion of this approach to mining this data-set with lists of the identified probe sets and statistical analysis has been published (Almon et al. 2004). Extensive literature searches of the 653 probe sets identified by this mining method yielded 29 probe sets whose regulation is clearly related to insulin resistance. These 29 identified probe sets were then clustered using gene-tree analysis in GeneSpring 6·2.

\section{Results}

Figure 1A shows the plasma MPL concentrations in ADX rats as a function of time after the single iv bolus dose of $50 \mathrm{mg} / \mathrm{kg}$. These data demonstrate that the drug is entirely eliminated by $7 \mathrm{~h}$ following dosing. Figure $1 \mathrm{~B}$ shows a transient increase in the plasma glucose concentration that begins about $2 \mathrm{~h}$ following dosing and lasts for $9 \mathrm{~h}$. Figure $1 \mathrm{C}$ demonstrates an increase in plasma insulin that begins between 2 and $3 \mathrm{~h}$ following dosing and does not return to baseline until between 30 and $48 \mathrm{~h}$.

All glucocorticoid-regulated probe sets were identified using their accession numbers and an extensive literature search (Medline) was carried out on each one. In the course of this literature search 29 probe sets coding for 22 gene transcripts were found that relate to insulin resistance. Eight of these gene transcripts were down-regulated (Table 1A), 12 were up-regulated (Table 1B), and two showed biphasic regulation (Table 1C).

Figure 2 shows the gene tree derived from the GeneSpring program for these 29 probe sets (29 probe sets 

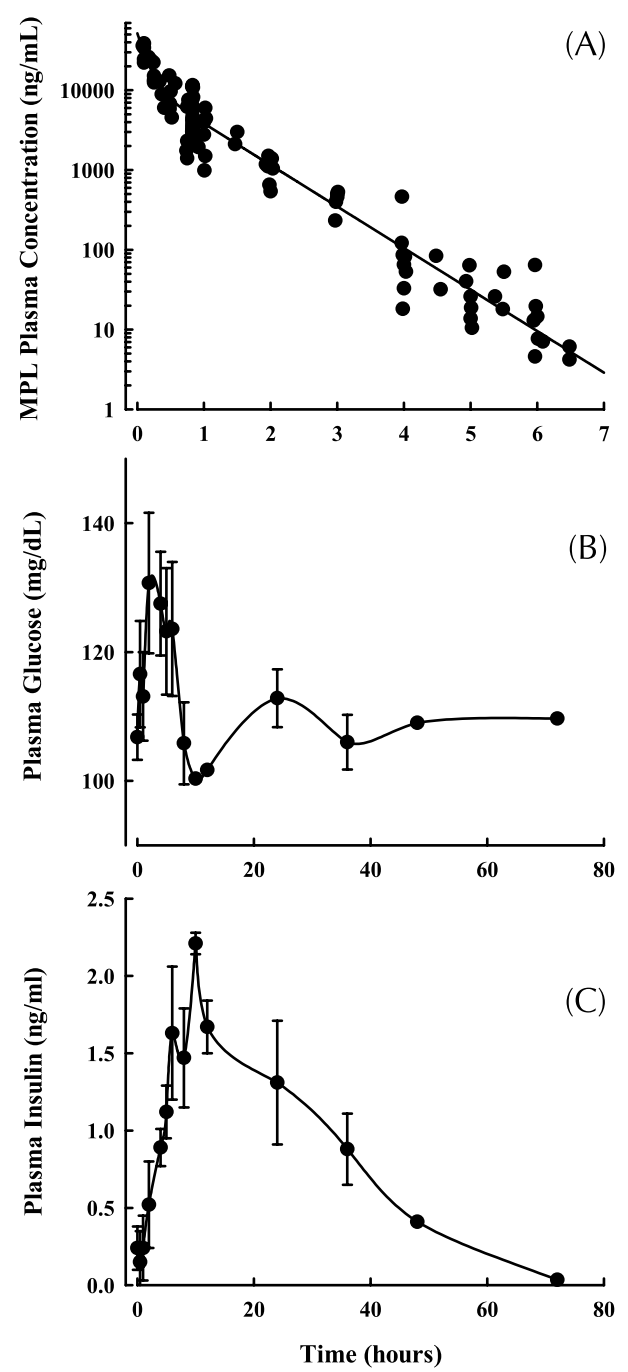

Figure 1 Plasma concentrations of (A) MPL, (B) glucose, and (C) insulin versus time after a $50 \mathrm{mg} / \mathrm{kg}$ i.v. bolus dose of $\mathrm{MPL}$ in rats.

at 17 time points). This tree was constructed using a Pearson correlation. The $x$-axis presents the 17 time points studied in rank order from left to right. Vehicle controls are nominally referred to as time 0 . As pointed out above, each time point is equally spaced and therefore does not represent the true temporal relationship between points. The $y$-axis presents the mean of the normalized value at each time point for each of the individual probe sets, represented by color and clustered by similarity. In this view, the color yellow represents a value of 1 , progression towards red represents values that exceed 1, and progression towards blue represents values that decline towards 0 . The intensity of the color reflects the intensity of the original signal. To the immediate left of the gene tree is a schematic tree of the relationship of all probes to each other based on expression-pattern similarity (represented in green). Gene trees provide an excellent global view of all of the probe sets and their relationship to each other. At the bottom there is a group of 10 probe sets with sustained sequences of blue, which indicates down-regulation. An enlargement of this section of the tree (Fig. 3, left) shows that two probe sets for mitochondrial glycerol-3-phosphate dehydrogenase 2 (mGDPH) sit side by side and two probe sets for extracellular signal-related kinase 3 (ERK 3) also sit side by side. Above these 10 probe sets in Fig. 2 are 19 probe sets that in general appear to show enhanced regulation. However, three of these probe sets also show apparent down-regulation at the 30-, 48-, and 72-h points and thus appear to have a biphasic signature, a phenomenon we have described previously (Jin et al. 2003). An enlargement of the section of the tree containing these three probe sets (Fig. 3, middle) shows that two of the probe sets are for uncoupling protein 3 (UCP3) and one is for pyruvate dehydrogenase kinase isoenzyme 4 (PDK4). Figure 3 (right) shows an enlargement of the remainder of the tree containing the probe sets with enhanced regulation. This group contains two probe sets each for type-1A angiotensin II receptor (AT1A), p38 mitogen-activated protein kinase (p38 MAPK), peroxisome proliferator-activated receptor $\delta(\operatorname{PPAR} \delta)$, and protein tyrosine phosphatase type 1B (PTP1B). In all cases except for p38 MAPK, the two probe sets for the same gene sit side by side, indicating an extremely high similarity of pattern. Interestingly, probe sets for CCAAT/enhancer-binding proteins (C/ EBPs) $\beta$ and $\delta$ also sit next to each other on the tree. Table 1 shows the names and probe-set identifiers for the down-regulated group, the up-regulated group, and the biphasic group.

The 29 probe sets presented in Figs 2 and 3 were grouped into four categories based on their function: those involved in signal transduction mechanisms, those that act as transcription factors, those that are related to carbohydrate or lipid metabolism, and those which influence blood flow. Figs 4-7 present mean normalized intensities (three animals per time point) for each gene at the 16 time points examined. Error bars represent standard deviations of those means. Figure 4 shows the temporal signatures of the six gene transcripts related to signal transduction. Two of these, insulin receptor substrate-1 (IRS-1) and ERK3, were down-regulated following MPL treatment. The remaining four transcripts in this group showed enhanced expression following corticosteroid treatment. Enhanced transcripts include p38 MAPK, PTP1B, leukocyte common antigen-related protein (LAR), and interleukin 6 receptor (IL6R1).

There were five transcription factors whose temporal patterns of regulation were related to insulin resistance (Fig. 5). Transcription factor transcripts which were down-regulated by corticosteroid treatment include steroid receptor-enhancing binding protein-1c (SREBP$1 c)$ and retinoic acid $X$ receptor $\gamma-1(\operatorname{RXR} \gamma)$. Enhanced 
Table 1 MPL-regulated transcripts relating to insulin resistance

(A)

Accession $\mathbf{n}$
X58375
L16995
AJ223083
D 89655
U36771
U67995
X78593
M64301

(B)

\section{Accession no.}

L36664

M33962

M60103

M64711

M86912

U40064

M33648

M24067

S77528

Al045030

M58587

U73142

(C)

Accession no.

AF030163

AF034577

Down-regulated transcripts

\begin{tabular}{|c|c|c|}
\hline Gene transcript & Abbreviation & Functional category \\
\hline Insulin receptor substrate-1 & IRS-1 & Signal transduction \\
\hline Steroid receptor enhancing binding protein-1c & SREBP-1C, ADD1 & Transcription factor \\
\hline Retinoic acid $X$ receptor $\gamma-1$ & $\mathrm{RXR} \gamma$ & Transcription factor \\
\hline Scavenger receptor class B1 & FAT, CD36 & Metabolism \\
\hline Glycerol-3-phosphate acyltransferase & GPAT & Metabolism \\
\hline Stearyl-CoA desaturase 2 & SCD2 & Metabolism \\
\hline Mitochondrial glycerol-3-phosphate dehydrogeanse 2 & mGDPH & Metabolism \\
\hline Extracellular signal related kinase 3 & ERK3 & Signal transduction \\
\hline
\end{tabular}

\section{Up-regulated transcripts}

\section{Gene transcript}

Kininase II

Protein tyrosine phosphatase type 1B

Leukocyte common antigen-related protein

Endothelin-1

Type-1A angiotensin II receptor

Peroxisome proliferator-activated receptor $\delta$

3-Hydroxy-3-methylglutaryl-CoA synthase

Plasminogen-activator inhibitor 1

CCAAT/enhancer-binding protein $\beta$

CCAAT/enhancer-binding protein $\delta$

Interleukin 6 receptor

p38 Mitogen-activated protein kinase

\begin{tabular}{l} 
Abbreviation \\
\hline ACE \\
PTP1B \\
LAR, LAR PTPase, Ptprf \\
ET-1 \\
AT1A \\
PPAR $\delta$ \\
HMG-CoA synthase \\
PAI-1 \\
C/EBP $\beta$, NFIL6 \\
C/EBP $\delta$, NFIL6 $\beta$ \\
IL6R1 \\
p38 MAPK
\end{tabular}

Functional category

Blood flow

Signal transduction

Signal transduction

Blood flow

Blood flow

Transcription factor

Metabolism

Blood flow

Transcription factor Transcription factor Signal transduction Signal transduction

\section{Biphasic-regulated transcripts}

\begin{tabular}{llll}
\hline Gene transcript & Abbreviation & & Functional category \\
& & & Metabolism \\
Uncoupling protein 3 & UPC3 & & Metabolism \\
Pyruvate dehydrogenase kinase isoenzyme 4 & PDK4 & &
\end{tabular}

expression following steroid treatment occurred with $\operatorname{PPAR} \delta, \mathrm{C} / \mathrm{EBP} \beta$, and $\mathrm{C} / \mathrm{EBP} \delta$ transcripts.

Seven regulated transcripts were found that relate to carbohydrate and lipid metabolism (Fig. 6). Four transcripts in this group exhibited corticosteroid-induced down-regulation: scavenger receptor class B1 (fatty acid transporter; FAT), mitochondrial glycerol-3-phosphate acyltransferase (GPAT), mGDPH, and stearyl-CoA desaturase 2 (SCD2). One transcript, mitochondrial 3-hydroxy-3-methylglutaryl-CoA synthase (HMG-CoA synthase), was enhanced following steroid treatment. In addition, both UCP3 and PDK4 showed biphasic regulation, with an initial enhanced expression followed by expression levels that fell below baseline.

The last functional group contained four transcripts, all of which showed enhanced expression and influence blood flow in the musculature (Fig. 7). These transcripts may be expressed in the muscle, the muscle vasculature, or both.
These include kininase II, AT1A, endothelin-1 (ET-1), and plasminogen-activator inhibitor 1 (PAI-1).

\section{Discussion}

A population of ADX animals was injected with a single bolus dose of MPL, groups of three animals were killed at each of 16 time points over a 72-h period, and muscles from MPL-treated samples were compared with vehicletreated controls. ADX animals were used to eliminate the circadian oscillation and provide a stable baseline. This allowed us to identify gene transcripts that deviated from the baseline following drug treatment and determine the duration of time it takes to return to that baseline. The drug was cleared $7 \mathrm{~h}$ following dosing. In another cohort of animals treated alike, elevated concentrations of glucose were found in the blood after about $9 \mathrm{~h}$. The pattern of 


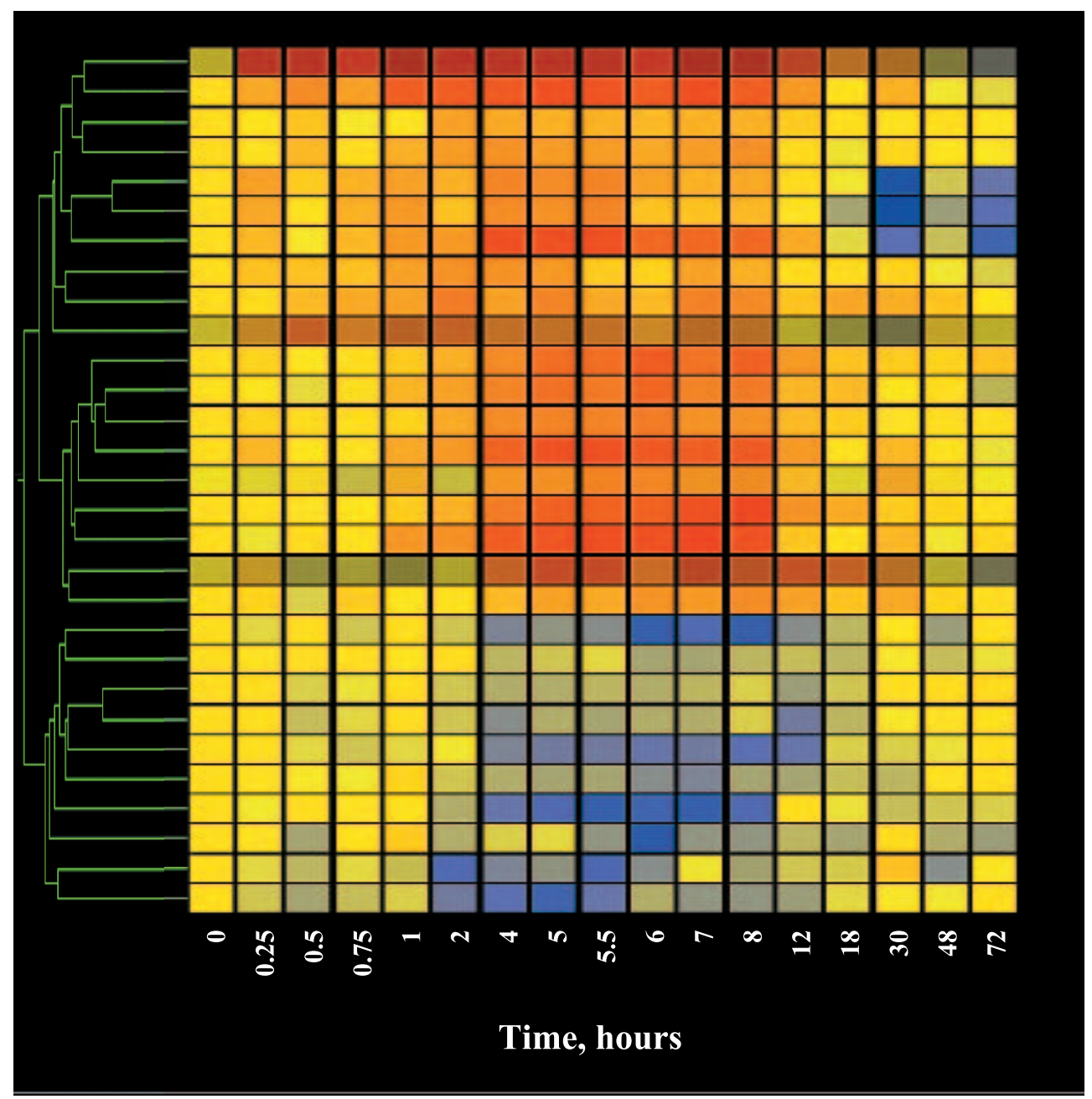

Figure 2 Gene-tree representation of the 29 probe sets identified to be related to insulin resistance in skeletal muscle. The gene tree represents the averaged normalized values of each of the 29 probe sets at 17 different time points following MPL treatment, grouped by pattern similarities. The $y$-axis represents individual probe sets, with color representing relative intensity (yellow represents no change from control, progression towards red indicates increased expression, and progression towards blue represents decreased expression versus control values). The $x$-axis ranks the samples in sequence of time following MPL treatment.

elevated glucose is consistent with the origin being corticosteroid-induced gluconeogenesis by the liver and kidney. Elevated concentrations of insulin were also found in the blood lasting about $48 \mathrm{~h}$. The rise in insulin is consistent with the increased blood glucose. However, the long-lasting duration of the elevated insulin concentration was unexpected. At present it is not possible to determine if this persistence of plasma insulin is due to continued release from the pancreas or reduced elimination. In either case, because placebo controls did not demonstrate such a pattern, MPL must in some way be involved. Interestingly, such sustained elevation of insulin would contribute to insulin resistance, possibly through down-regulation of elements of the cascade leading to glucose transport. The fact that a single dose of MPL results in such a persistent hyperinsulinemia suggests that when dosing is repetitive there may be a cumulative effect.

The use of microarray technology within the context of a time-series approach allows one to evaluate the cascade of transcriptional events in the development and decay of different aspects of gene expression that relate to the complex physiological or pathological process being studied. Temporal profiles are particularly relevant in this case because 11 of the 22 gene transcripts were for proteins involved in signal transduction or transcription regulation. These temporal profiles should allow us to begin to evaluate downstream consequences of expression changes in these signaling cascades. We have organized these 


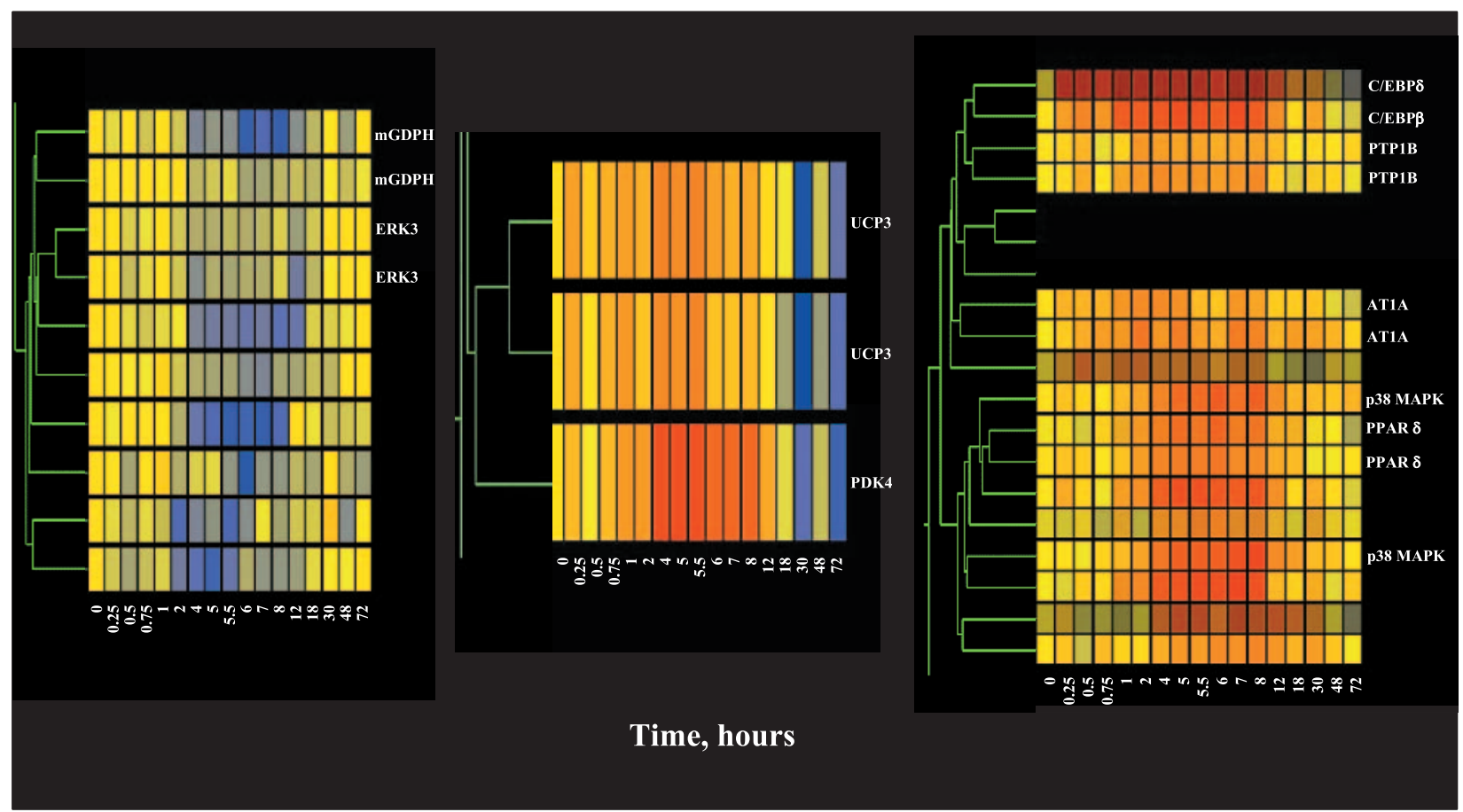

Figure 3 Magnified views of various regions of gene tree presented in Fig. 2. The left-hand panel shows a magnification of the down-regulated probe sets present on the gene tree in Fig. 2. The middle panel presents an enlargement of the three probe sets from Fig. 2 that exhibit biphasic regulation. The right-hand panel shows a magnified view of up-regulated probe sets. Abbreviations are given in Table 1.

22 transcripts relating to insulin resistance into four functional categories: signal transduction, transcription regulation, carbohydrate/fat metabolism, and regulation of blood flow.

Six gene transcripts related to signal transduction were regulated. These six transcripts either play a direct role in insulin signaling (IRS-1 and ERK3) or have been implicated in insulin sensitivity/insulin resistance (PTP1B, LAR, p38 MAPK, IL6R1). The decline in IRS-1, a central element in insulin signaling, will severely inhibit insulin-directed glucose uptake (Sesti 2000, Araki \& Tsuruzoe 2002, Shirakami et al. 2002). It has been reported previously that chronic corticosteroid treatment reduces the amount of IRS-1 in skeletal muscle (Giorgino et al. 1993, Dupont et al. 1999), consistent with the down-regulation in the IRS-1 transcript seen here with a single bolus dose of MPL. Down-regulation of ERK3 transcripts following MPL administration should also contribute directly to reduced insulin signaling (Boulton et al. 1991, Turgeon et al. 2000). In contrast, expression of PTP1B, p38 MAPK, and LAR were increased. An increase in these transcripts would contribute to inactivation of insulin signaling at various levels and promote insulin resistance (Ahmad \& Goldstein 1995, Ahmad et al. 1997, Chen et al. 1999, Egawa et al. 2001, Fujishiro et al. 2001, Goldstein 2001, Di Paola et al. 2002). The final transcript in this category is IL6R1, whose expression potentially enhances interleukin-6 sensitivity. Interleukin6 has been shown to interfere with insulin-induced kinase cascades (Mooney et al. 2001, Senn et al. 2002), and elevated levels of plasma interleukin-6 are also associated with insulin-resistant states (Senn et al. 2002, 2003). Together, the changes in these six gene transcripts present a polygenic picture of greatly impaired insulin signaling in skeletal muscle.

The expressions of transcripts for five transcription factors with direct relevance to insulin resistance were also regulated. SREBP-1c, which was down-regulated following steroid treatment, is a helix-loop-helix transcription factor that mediates insulin effects on gene expression in liver, skeletal muscle, and other tissues. This gene at least in part mediates the insulin-induced increased expression of glycolytic and lipogenic enzyme genes (Guillet-Deniau et al. 2002, Shimano 2002). The early decreased expression of SREBP-1c following corticosteroid treatment would therefore presumably decrease some insulininduced transcriptional effects. To our knowledge this is the first report demonstrating that corticosteroids regulate the expression of this gene. $\operatorname{RXR} \gamma$, which was also down-regulated, is a transcription factor that functions as a homodimer or as a heterodimer with PPAR $\alpha$ and PPAR $\gamma$ in skeletal muscle (Dowhan et al. 1994, Cha et al. 2001). 


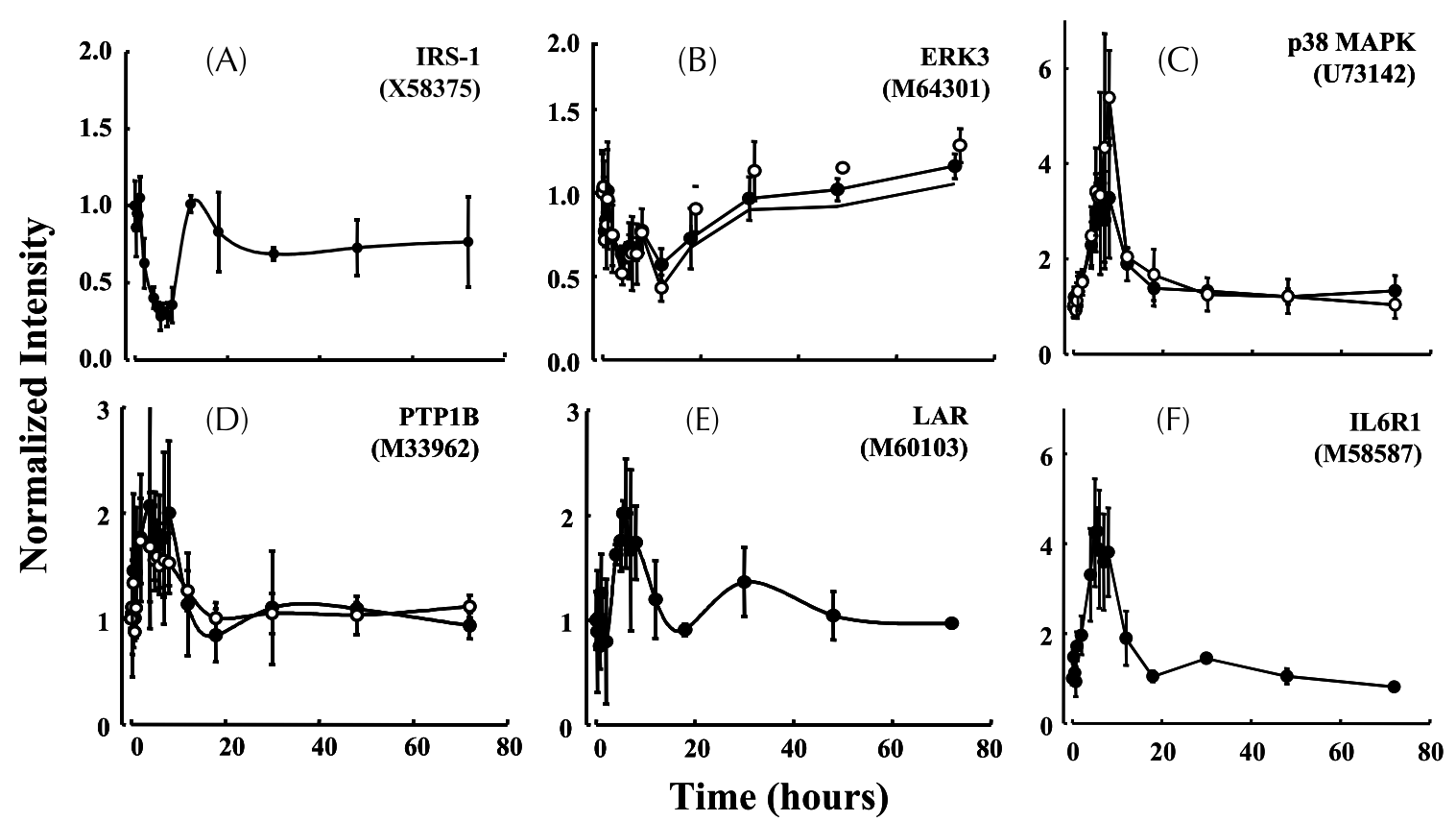

Figure 4 Linear plots of the six gene transcripts related to signal transduction as a function of time following MPL administration. The $x$-axis represents time after MPL administration, and the $y$-axis average normalized intensities from Affymetrix array analysis. Error bars represent standard deviations of the mean. Numbers in parentheses are accession numbers. Abbreviations are given in Table 1.

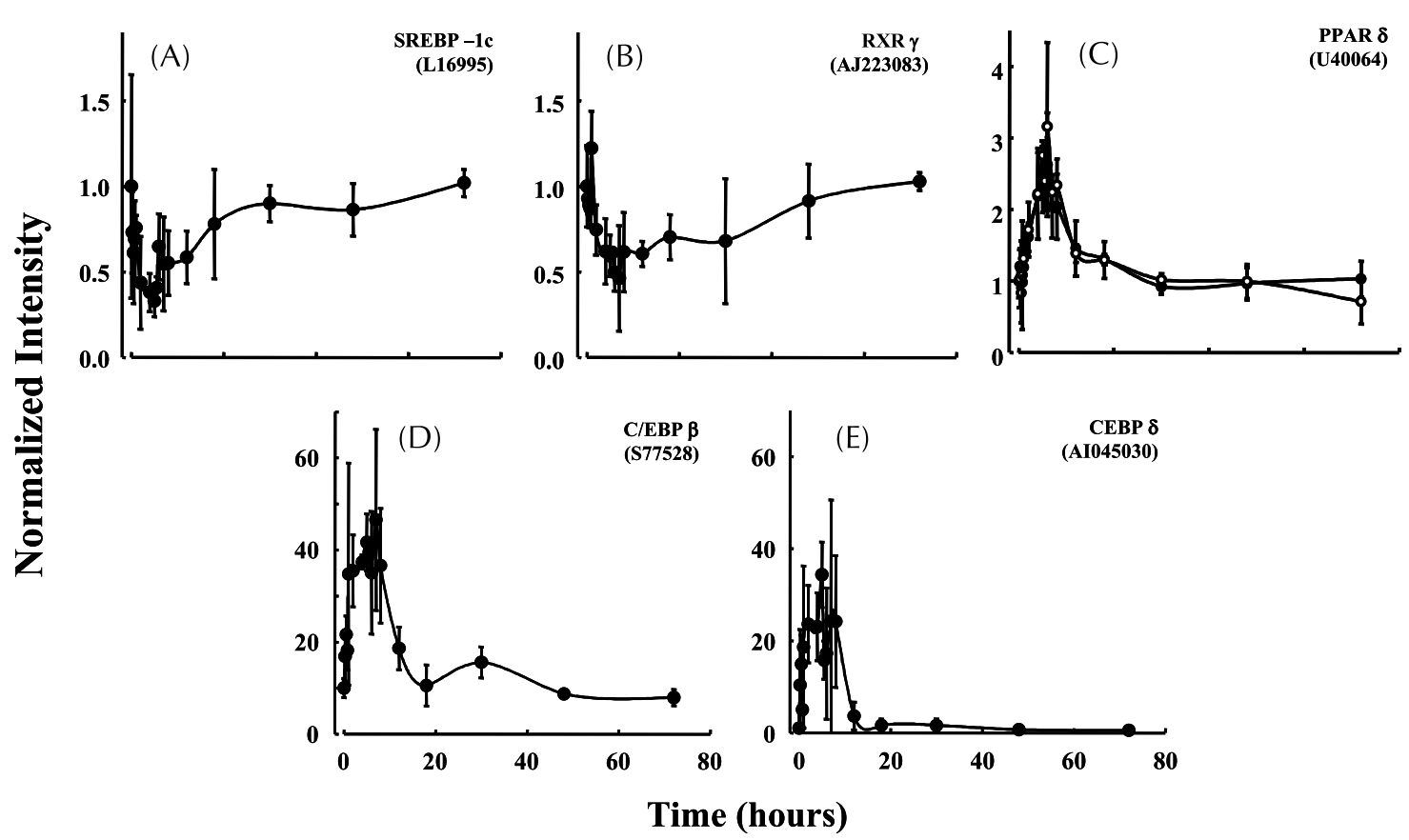

Figure 5 Linear plots of the five transcription factor gene transcripts as a function of time following MPL administration. Axes and symbols are as defined in Figure 4. Numbers in parentheses are accession numbers. Abbreviations are given in Table 1. 


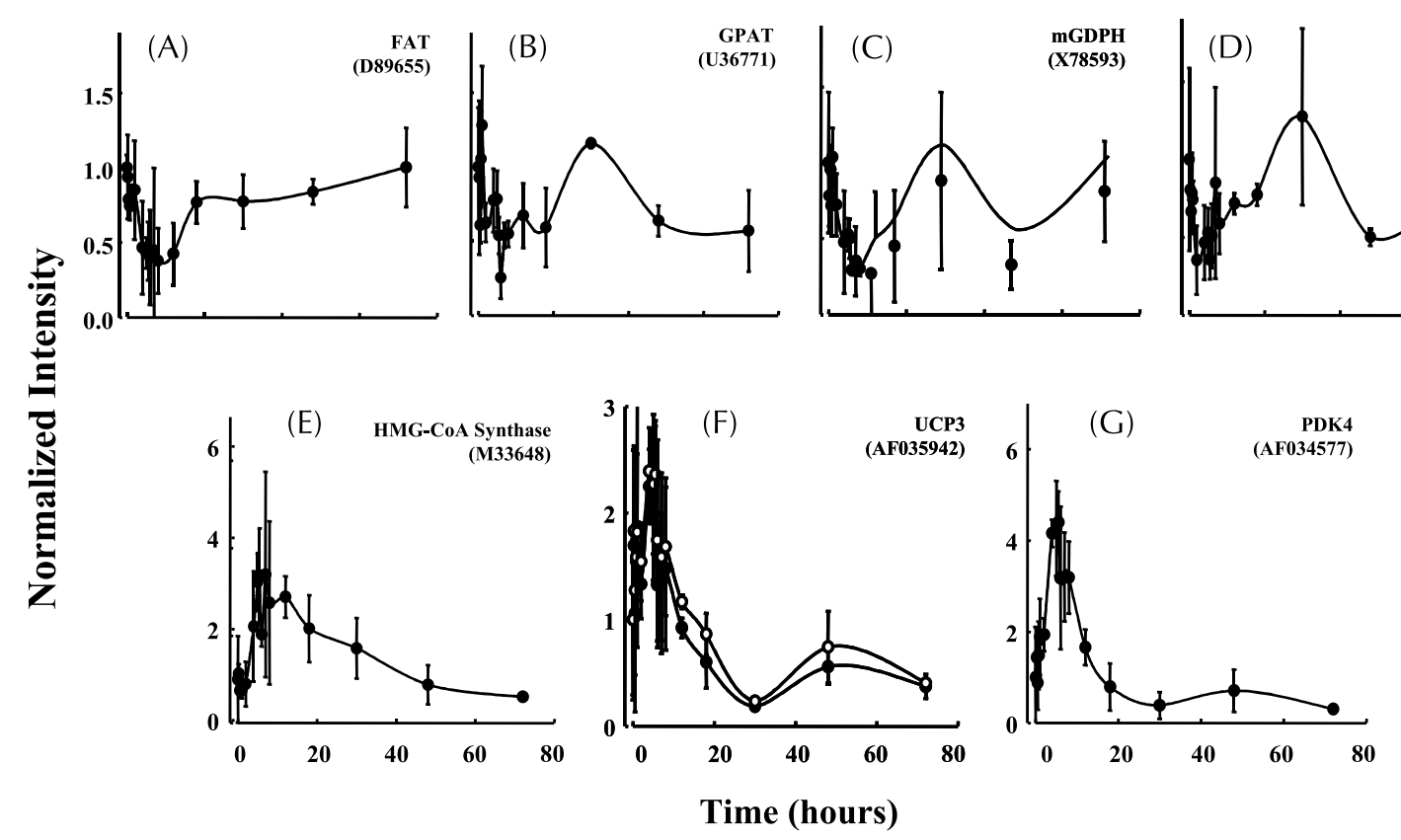

Figure 6 Linear plots of the seven gene transcripts related to carbohydrate and lipid metabolism as a function of time following MPL administration. Axes and symbols are as defined in Figure 4. Numbers in parentheses are accession numbers. Abbreviations are given in Table 1.

This transcription factor regulates several genes involved in energy metabolism, including FAT, and influences muscle insulin sensitivity (Cha et al. 2001, Singh Ahuja et al. 2001). Three transcription factors (PPAR $\delta, C / E B P \beta$, and $\mathrm{C} / \mathrm{EBP} \delta$ ) are up-regulated; up-regulation of all three are associated with increased lipid metabolism in skeletal muscle and have also been associated with insulin resistance (Zador et al. 1998, Muoio et al. 2002, Penner et al. 2002).

The next group includes genes related to carbohydrate and lipid metabolism. These probes, together with the transcription factors discussed above, present a picture of a shift in the muscle away from glycolysis towards $\beta$-oxidation, consistent with an insulin-resistant state. Four of the gene transcripts in this group are downregulated (FAT/CD36, GPAT, SCD2, $\mathrm{mGDPH}$ ), one is up-regulated (HMG CoA synthetase), and two show biphasic regulation (UPC3, PDK4). The expression of three of the four transcripts whose expression is decreased (FAT/CD36, SCD2, GPAT) relate to increased utilization of lipids for energy generation, and in some cases have been directly linked to decreased insulin sensitivity (Cha et al. 2001, Lewin et al. 2001, Mooney et al. 2001, Singh Ahuja et al. 2001, Kim et al. 2002). The regulation of all three of these genes is also mediated by SREBP-1c and RXR (Cha et al 2001, Ikeda et al. 2002). The last down-regulated transcript in this group is mGDPH. Down-regulation of this transcript is consistent with decreased glycolytic activity associated with insulin resistance (Brown et al. 1994). Two transcripts in this group (UPC3, PDK4) have a temporal signature suggesting biphasic regulation. Both transcripts show a rapid enhanced expression that returns to baseline by $12 \mathrm{~h}$, then declines below baseline by $30 \mathrm{~h}$, and remains low for the remainder of the 72-h period. The first is UCP3, which is a transporter protein that creates a leak across the mitochondrial inner membrane. This uncouples oxidative phosphorylation allowing the energy to be dissipated as heat (Dulloo et al. 2001). Enhanced expression of UCP3 in skeletal muscle has been associated with obesity and type 2 diabetes in humans (Bao et al. 1998), and elevated levels of UCP3 in skeletal muscle have been linked closely to insulin resistance in several insulin-resistant states (Bao et al. 1998, Samec et al. 1999, Oberkofler et al. 2000, Fabris et al. 2001, Strommer et al. 2001). In skeletal muscle increased expression of UCP3 is associated with the channeling of fuel utilization towards fat and away from carbohydrates (Weigle et al. 1998), and the initial up-regulation of this transcript is consistent with insulin resistance. The second biphasic transcript in this group is PDK4. This enzyme inactivates the mitochondrial pyruvate dehydrogenase complex by phosphorylation. Since the pyruvate dehydrogenase complex regulates the oxidative disposal of glucose, its inactivation by PDK4 can limit glucose use by skeletal muscle (Sugden et al. 1995). Insulin down-regulates the expression of PDK4 in skeletal muscle while high-fat diets tend to increase it (Majer et al. 1998). There is considerable interest in regulating PDK4 as an approach to the treatment of type 2 diabetes 


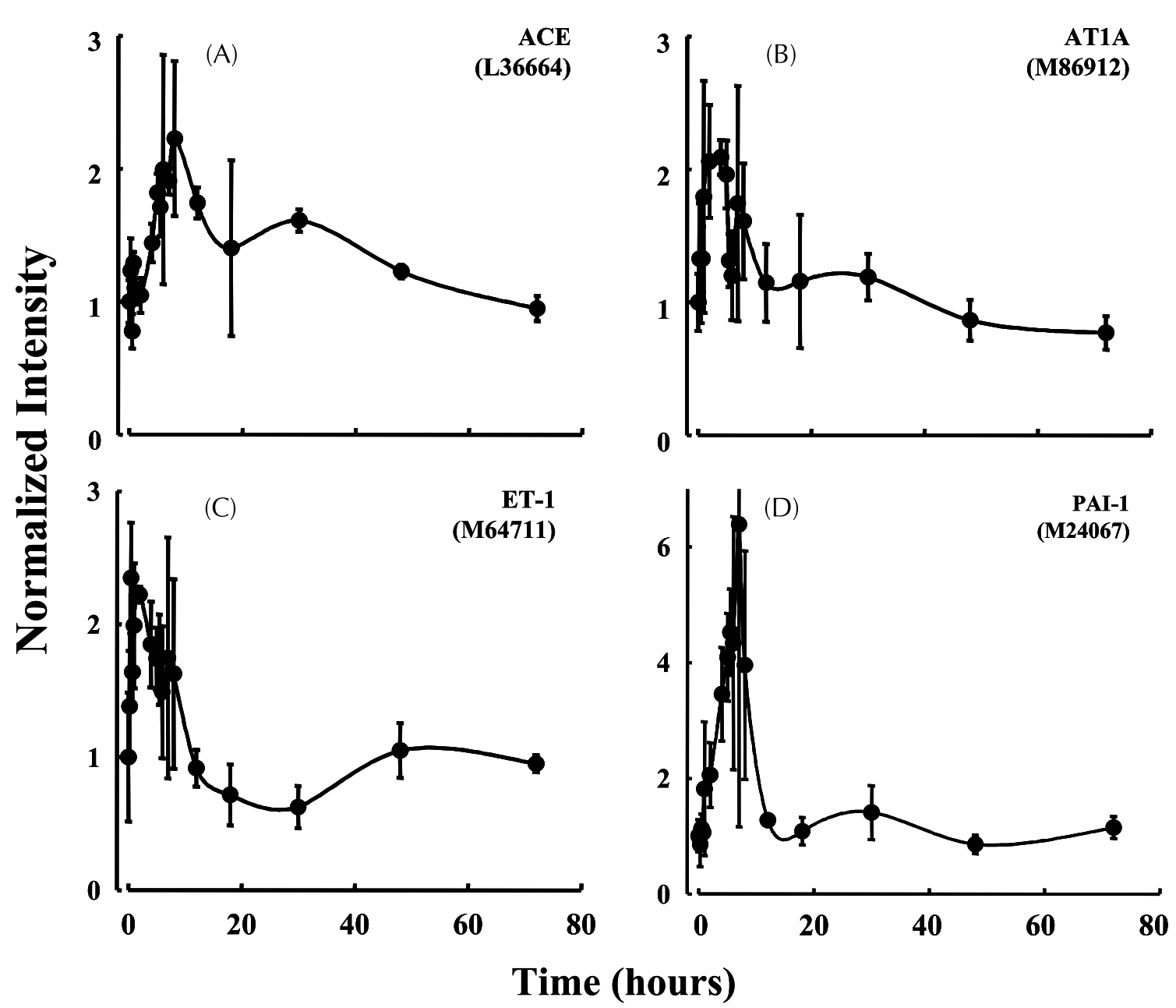

Figure 7 Linear plots of the four gene transcripts related to muscle blood flow as a function of time following MPL administration. Axes and symbols are as defined in Figure 4. Numbers in parentheses are accession numbers. Abbreviations are given in Table 1.

(Oshida et al. 1999, Sreenan et al. 1999, Sugden \& Holness 2002). The last transcript in this group is HMG-CoA synthase, which shows enhanced expression. HMG-CoA synthase is the key regulated enzyme in the synthesis of ketone bodies (Hegardt 1999, Challis et al. 2001). Although the liver is generally considered to be the site of ketone-body synthesis, it has been estimated that skeletal muscle may be responsible for as much as $25 \%$ of ketonebody production in poorly controlled diabetes (Nosadini et al. 1985, Bailey et al. 1990), and therefore increased expression of this transcript following corticosteroid administration is also consistent with insulin resistance.

The last group of transcripts consists of four that may be skeletal muscle in origin, vascular endothelial in origin, or both. All four showed enhanced expression and are clearly associated with insulin resistance. The first is kininase II (EC 3·4 15·1), which converts angiotensin I to angiotensin II. Kininase II, also known as angiotensin-converting enzyme (ACE), is generally thought of as an ectoenzyme bound to vascular endothelial cells (Sun et al. 1994). However, it has been reported that skeletal muscle membranes also contain this enzyme (Dragovic et al. 1996). Regardless of the origin of this transcript, inhibitors of this enzyme have been shown to improve glucose uptake into skeletal muscles (Bottermann \& Classen 1991, Dietze et al. 1996). Thus the enhanced expression of kininase II would contribute to insulin resistance. The second is ET-1, which is a potent vasoconstrictor. Synthesis of ET-1 has been reported in several organs such as heart, lung, and skeletal muscle suggesting that it may also play a role as a local regulator of blood flow (Sakurai et al. 1991, Guo et al. 1998). Elevated levels of ET-1 are also associated with insulin resistance (Ottosson-Seeberger et al. 1997, Idris et al. 2001), reduced blood flow to the musculature and thus reduced glucose disposal (Santure et al. 2002). The third is AT1A. This receptor mediates the vasoconstrictor 
activity of angiotensin II, and blocking AT1A improves glucose disposal (Hoenack \& Roesen 1996, Brown et al. 2002). Interestingly, gene therapy with AT1A antisense DNA has been shown to improve insulin sensitivity in the high-fructose-fed rat model for glucose intolerance (Katovich et al. 2001). The last transcript in this group is PAI-1, which binds and inactivates the plasminogen activator urokinase, a major control point in the regulation of fibrinolysis. Elevated levels of PAI-1 are common in insulin-resistant patients and are a high risk factor for infarction (Peltonen et al. 1995, Thogersen et al. 1998, Shirakami et al. 2002).

In the present report we have used microarrays to profile the changes in gene expression that occur in rat skeletal muscle and which relate to insulin resistance following a single dose of MPL. In contrast to chronic treatment, temporal profiling along with the use of microarrays provides a broad 'motion picture' of the development and decay of components of corticosteroid-induced insulin resistance. This picture portrays multiple points of direct interference with the insulin signaling cascade with the reduced expression of IRS-1 and perhaps ERK3. It also portrays multiple points of interference with insulin signaling through the enhanced expression of PTP1B, LAR, and perhaps kininase II, AT1A and p38 MAPK. There are direct expression changes that lead to the reduction in the use of glucose by skeletal muscle with the decrease in mGDPH and the increase in PDK4. Similarly, the temporal profile illustrates the shift of skeletal muscle towards fat for energy production that includes reductions in the expression of GPAT, SCD2, and FAT along with enhanced expression of UCP3 and HMG-CoA synthase. The results also provide insight into the reduced blood flow to skeletal muscle that impairs glucose disposal and contributes to the hypertension that develops with chronic corticosteroid use. Increases in kininase II, ET-1, AT1A, and PAI-1 provide a comprehensive picture of reduced muscle blood flow and the foundation for infarction. Finally, the temporal profile provides a perspective on the complex transcriptional regulation responsible for these changes in gene expression. In addition to the effects of corticosteroids on gene expression mediated by the activated glucocorticoid receptor interacting with glucocorticoid-responsive elements there is the decrease in two transcription factors (SREBP-1 and RXR $\gamma$ ), both of which enhance the expression of genes that increase insulin sensitivity. There were also increases in $\operatorname{PPAR} \delta$, $\mathrm{C} / \mathrm{EBP} \beta$ nuclear factor interleukin 6 (NFIL6), C/EBP $\delta$ (NFIL6 $\beta$ ), and IL6R1, all of which enhance the expression of genes promoting the use of fat. The combination of IL6R1 along with the two NFIL6 transcription factors suggests that corticosteroid-induced insulin resistance may involve enhancing the sensitivity of skeletal muscle to other systemic factors that promote insulin resistance. By using a single bolus dose of MPL in ADX animals we were able to determine the duration of the transcrip- tional responses. The observation that some responses lasted as long as $30-40 \mathrm{~h}$ suggests that repeated dosing with daily divided or daily dosing regimens may lead to accumulating effects.

Besides the pharmacological use of corticosteroids there are other conditions that involve insulin resistance. Cachexia, sepsis, and trauma all result in insulin resistance with glucocorticoids clearly involved in these processes (Martinez-Riquelme \& Allison 2003). In addition, type 2 diabetes mellitus, which has diffuse genetic and environmental (diet and exercise) origins, is a syndrome of insulin resistance. Observations indicating that insulin resistance is part of the metabolic syndrome stemming from prenatal corticosteroid exposure suggest a role for the hypothalmic/ pituitary/adrenal axis, in at least some cases of type 2 diabetes (Challis et al. 2001, Bertram \& Hanson 2002, Newnham et al. 2002).

Insulin resistance, regardless of cause, involves a disruption of the systemic balance in fuel utilization between carbohydrates and fats. Because skeletal muscle is responsible for $75-80 \%$ of the insulin-mediated disposal of glucose, all types of insulin resistance must involve this tissue. Although corticosteroid-induced insulin resistance is not a perfect model for all insulin-resistant states, it does provide an insightful picture of the polygenic expression changes that can be involved in the expression of insulin resistance. It is of interest that the numerous and diverse transcriptional alterations are produced by MPL with time frames that temporally correspond to the transient hyperglycemia and hyperinsulinemia. Further explorations of the relationships between systemic manifestations of insulin resistance and transcriptional alterations in skeletal muscle and other tissues are of importance to understanding and perhaps identifying additional drug targets for this pathology with polygenic origins. Understanding the temporal cascade of events may also aid in designing dosing regimens that minimize this adverse consequence of the pharmacological use of corticosteroids.

\section{Funding}

This work was supported by grants GM 24211 and GM67650 from the National Institute of General Medical Sciences, National Institutes of Health. This data-set was developed under the auspices of a grant from the NHLBI/ National Institutes of Health Programs in Genomic Applications U01 HL66614. The authors declare that there is no conflict of interest that would prejudice the impartiality of this scientific work.

\section{Acknowledgements}

We would like to acknowledge the expert assistance of Ms Suzette Mis in manuscript preparation, and of Ms Nancy Pyszczynski in the conduct of animal studies presented here. 


\section{References}

Ahmad F \& Goldstein BJ 1995 Increased abundance of specific skeletal muscle protein-tyrosine phosphatases in a genetic model of insulin-resistant obesity and diabetes mellitus. Metabolism: Clinical and Experimental 44 1175-1184.

Ahmad F, Azevedo JL, Cortright R, Dohm GL \& Goldstein BJ 1997 Alterations in skeletal muscle protein-tyrosine phosphatase activity and expression in insulin-resistant human obesity and diabetes. Journal of Clinical Investigation 100 449-458.

Almon RR, DuBois DC, Brandenburg EH, Shi W, Zhang S, Straubinger RM \& Jusko WJ 2002 Pharmacodynamics and pharmacogenomics of diverse receptor-mediated effects of methylprednisolone in rats using microarray analysis. Journal of Pharmacokinetics and Pharmacodynamics 29 103-129.

Almon R, DuBois D, Piel W \& Jusko W 2004 The genomic response of skeletal muscle to methylprednisolone using microarrays: tailoring data mining to the structure of the pharmacogenomic time series. Pharmacogenomics 5 525-552.

Araki E \& Tsuruzoe K 2002 Polymorphisms in insulin receptor substrate-1 (IRS-1) gene. Nippon Rinsho - Japanese Journal of Clinical Medicine 60 559-564.

Bailey JW, Haymond MW \& Miles JM 1990 Metabolism of ketone bodies by skeletal muscle in starvation and uncontrolled diabetes. Metabolism: Clinical and Experimental 39 1039-1043.

Bao S, Kennedy A, Wojciechowski B, Wallace P, Ganaway E \& Garvey WT 1998 Expression of mRNAs encoding uncoupling proteins in human skeletal muscle: effects of obesity and diabetes. Diabetes 47 1935-1940.

Baxter J 2000 Advances in glucocorticoid therapy. Advances in Internal Medicine 45 317-349.

Beck-Nielsen H, Hother-Nielsen O \& Staehr P 2002 Is hepatic glucose production increased in type 2 diabetes mellitus? Current Diabetes Reports 2 231-236.

Bertram CE \& Hanson MA 2002 Prenatal programming of postnatal endocrine responses by glucocorticoids. Reproduction 124 459-467.

Bialis M \& Routledge P 1998 Adverse effects of corticosteroids. Adverse Drug Reactions and Toxicological Reviews 17 227-235.

Bottermann P \& Classen M 1991 Diabetes mellitus and arterial hypertension. In search of the connecting link. Zeitschrift fur die Gesamte Innere Medizin und Ihre Grenzgebiete 46 558-562.

Boulton TG, Nye SH, Robbins DJ, Ip NY, Radziejewska E, Morgenbesser SD, DePinho RA, Panayotatos N, Cobb MH \& Yancopoulos GD 1991 ERKs: a family of protein-serine/threonine kinases that are activated and tyrosine phosphorylated in response to insulin and NGF. Cell 65 663-675.

Brown LJ, MacDonald MJ, Lehn DA \& Moran SM 1994 Sequence of rat mitochondrial glycerol-3-phosphate dehydrogenase cDNA. Evidence for EF-hand calcium-binding domains. Journal of Biological Chemistry 269 14363-14366.

Brown NJ, Kumar S, Painter CA \& Vaughan DE 2002 ACE inhibition versus angiotensin type 1 receptor antagonism: differential effects on PAI-1 over time. Hypertension 40 859-865.

Cha BS, Ciaraldi TP, Carter L, Nikoulina SE, Mudaliar S, Mukherjee R, Paterniti Jr JR \& Henry RR 2001 Peroxisome proliferator-activated receptor (PPAR) gamma and retinoid $\mathrm{X}$ receptor (RXR) agonists have complementary effects on glucose and lipid metabolism in human skeletal muscle. Diabetologia 44 444-452.

Challis JR, Sloboda D, Matthews SG, Holloway A, Alfaidy N, Patel FA, Whittle W, Fraser M, Moss TJ \& Newnham J 2001 The fetal placental hypothalamic-pituitary-adrenal (HPA) axis, parturition and post natal health. Molecular and Cellular Endocrinology 185 135-144.

Chen H, Cong LN, Li Y, Yao ZJ, Wu L, Zhang ZY, Burke Jr TR \& Quon MJ 1999 A phosphotyrosyl mimetic peptide reverses impairment of insulin-stimulated translocation of GLUT4 caused by overexpression of PTP1B in rat adipose cells. Biochemistry 38 384-389.
Dietze GJ, Wicklmayr M, Rett K, Jacob S \& Henriksen EJ 1996 Potential role of bradykinin in forearm muscle metabolism in humans. Diabetes 45 S110-S114.

Di Paola R, Frittitta L, Miscio G, Bozzali M, Baratta R, Centra M, Spampinato D, Santagati MG, Ercolino T, Cisternino C et al. 2002 A variation in $3^{\prime}$ UTR of hPTP1B increases specific gene expression and associates with insulin resistance. American Journal of Human Genetics 70 806-812 [erratum appears in American Journal of Human Genetics (2002) 70 1388].

Dowhan DH, Downes M, Sturm RA \& Muscat GE 1994 Identification of deoxyribonucleic acid sequences that bind retinoid-X receptor-gamma with high affinity. Endocrinology 135 2595-2607.

Dragovic T, Minshall R, Jackman HL, Wang LX \& Erdos EG 1996 Kininase II-type enzymes. Their putative role in muscle energy metabolism. Diabetes 45 S34-S37.

Dulloo AG, Samec S \& Seydoux J 2001 Uncoupling protein 3 and fatty acid metabolism. Biochemical Society Transactions 29 785-791.

Dupont J, Derouet M, Simon J \& Taouis M 1999 Corticosterone alters insulin signaling in chicken muscle and liver at different steps. Journal of Endocrinology 162 67-76.

Egawa K, Maegawa H, Shimizu S, Morino K, Nishio Y, Bryer-Ash M, Cheung AT, Kolls JK, Kikkawa R \& Kashiwagi A 2001 Protein-tyrosine phosphatase-1B negatively regulates insulin signaling in 16 myocytes and Fao hepatoma cells. Journal of Biological Chemistry 276 10207-10211.

Eisen MB, Spellman PT, Brown PO \& Botstein D 1998 Cluster analysis and display of genome-wide expression patterns. PNAS 95 14863-14868.

Fabris R, Nisoli E, Lombardi AM, Tonello C, Serra R, Granzotto M, Cusin I, Rohner-Jeanrenaud F, Federspil G, Carruba MO et al. 2001 Preferential channeling of energy fuels toward fat rather than muscle during high free fatty acid availability in rats. Diabetes $\mathbf{5 0}$ 601-608.

Frauman A 1996 An overview of the adverse reactions to adrenal corticosteroids. Adverse Drug Reactions and Toxicological Reviews $\mathbf{1 5}$ 203-206.

Fujishiro M, Gotoh Y, Katagiri H, Sakoda H, Ogihara T, Anai M, Onishi Y, Ono H, Funaki M, Inukai K et al. 2001 MKK6/3 and p38 MAPK pathway activation is not necessary for insulin-induced glucose uptake but regulates glucose transporter expression. Journal of Biological Chemistry 276 19800-19806.

Giorgino F, Almahfouz A, Goodyear LJ \& Smith RJ 1993 Glucocorticoid regulation of insulin receptor and substrate IRS-1 tyrosine phosphorylation in rat skeletal muscle in vivo. Journal of Clinical Investigation 91 2020-2030.

Goldstein BJ 2001 Protein-tyrosine phosphatase 1B (PTP1B): a novel therapeutic target for type 2 diabetes mellitus, obesity and related states of insulin resistance. Current Drug Targets - Immune Endocrine and Metabolic Disorders 1 265-275.

Guillet-Deniau I, Mieulet V, Le Lay S, Achouri Y, Carre D, Girard J, Foufelle F \& Ferre P 2002 Sterol regulatory element binding protein-1c expression and action in rat muscles: insulin-like effects on the control of glycolytic and lipogenic enzymes and UCP3 gene expression. Diabetes $\mathbf{5 1}$ 1722-1728.

Guo Y, Cernacek P, Giaid A \& Hussain SN 1998 Production of endothelins by the ventilatory muscles in septic shock. American Journal of Respiratory Cell and Molecular Biology 19 470-476.

Hegardt FG 1999 Mitochondrial 3-hydroxy-3-methylglutaryl-CoA synthase: a control enzyme in ketogenesis. Biochemical Journal $\mathbf{3 3 8}$ $569-582$.

Hoenack C \& Roesen P 1996 Inhibition of angiotensin type 1 receptor prevents decline of glucose transporter (GLUT4) in diabetic rat heart. Diabetes 45 S82-S87.

Idris I, Patiag D, Gray S \& Donnelly R 2001 Tissue- and time-dependent effects of endothelin-1 on insulin-stimulated glucose uptake. Biochemical Pharmacology 62 1705-1708. 
Ikeda S, Miyazaki H, Nakatani T, Kai Y, Kamei Y, Miura S, Tsuboyama-Kasaoka N \& Ezaki O 2002 Up-regulation of SREBP-1c and lipogenic genes in skeletal muscles after exercise training. Biochemical and Biophysical Research Communications 296 395-400.

Jin JY, Almon RR, DuBois DC \& Jusko WJ 2003 Modeling of corticosteroid pharmacogenomics in rat liver using gene microarrays. Journal of Pharmacology and Experimental Therapeutics 307 93-109.

Katovich MJ, Reaves PY, Francis SC, Pachori AS, Wang HW \& Raizada MK 2001 Gene therapy attenuates the elevated blood pressure and glucose intolerance in an insulin-resistant model of hypertension. Journal of Hypertension 19 1553-1558.

Kim HJ, Miyazaki M \& Ntambi JM 2002 Dietary cholesterol opposes PUFA-mediated repression of the stearoyl-CoA desaturase-1 gene by SREBP-1 independent mechanism. Journal of Lipid Research 43 1750-1757.

Koistinen HA \& Zierath JR 2002 Regulation of glucose transport in human skeletal muscle. Annals of Medicine 34 410-418.

Lewin TM, Granger DA, Kim JH \& Coleman RA 2001 Regulation of mitochondrial sn-glycerol-3-phosphate acyltransferase activity: response to feeding status is unique in various rat tissues and is discordant with protein expression. Archives of Biochemistry and Biophysics 396 119-127.

Majer M, Popov KM, Harris RA, Bogardus C \& Prochazka M 1998 Insulin downregulates pyruvate dehydrogenase kinase (PDK) mRNA: potential mechanism contributing to increased lipid oxidation in insulin-resistant subjects. Molecular Genetics and Metabolism 65 181-186.

Martinez-Riquelme AE \& Allison SP 2003 Insulin revisited. Clinical Nutrition 22 7-15.

Mooney RA, Senn J, Cameron S, Inamdar N, Boivin LM, Shang Y \& Furlanetto RW 2001 Suppressors of cytokine signaling-1 and -6 associate with and inhibit the insulin receptor. A potential mechanism for cytokine-mediated insulin resistance. Journal of Biological Chemistry 276 25889-25893.

Muoio DM, MacLean PS, Lang DB, Li S, Houmard JA, Way JM, Winegar DA, Corton JC, Dohm GL \& Kraus WE 2002 Fatty acid homeostasis and induction of lipid regulatory genes in skeletal muscles of peroxisome proliferator-activated receptor (PPAR) alpha knock-out mice. Evidence for compensatory regulation by PPAR delta. Journal of Biological Chemistry 277 26089-26097.

Newnham JP, Moss TJ, Nitsos I \& Sloboda DM 2002 Antenatal corticosteroids: the good, the bad and the unknown. Current Opinion in Obstetrics and Gynecology 14 607-612.

National Institutes of Health 1985 Principles of Laboratory Animal Care. NIH publication 85-23. Bethesda, MD: National Institutes of Health.

Nosadini R, Avogaro A, Sacca L, Vigorito C, de Kreutzenberg S, Cobelli C, Toffolo G, Trevisan R, Tessari P, Tiengo A et al. 1985 Ketone body metabolism in normal and diabetic human skeletal muscle. American Journal of Physiology Endocrinology and Metabolism 249 E131-E136.

Oberkofler H, Neschen S, Esterbauer H, Waldhausl W, Patsch W \& Furnsinn C 2000 UCP3 gene expression does not correlate with muscle oxidation rates in troglitazone-treated Zucker fatty rats. Biochimica et Biophysica Acta 1517 113-118.

Oshida Y, Kako M, Nakai N, Shimomura Y, Li L, Sato J, Ohsawa I \& Sato Y 1999 Troglitazone improves insulin-stimulated glucose utilization associated with an increased muscle glycogen content in obese Zucker rats. Endocrine Journal 46 723-730.

Ottosson-Seeberger A, Lundberg JM, Alvestrand A \& Ahlborg G 1997 Exogenous endothelin-1 causes peripheral insulin resistance in healthy humans. Acta Physiologica Scandinavica 161 211-220.

Peltonen S, Lassila R, Rossi P, Salenius JP \& Lepantalo M 1995 Blood coagulation and fibrinolysis activation during sudden arterial occlusion of lower extremities-an association with ischemia and patient outcome. Thrombosis and Haemostasis $\mathbf{7 4}$ 1442-1446.

Penner G, Gang G, Sun X, Wray C \& Hasselgren PO 2002 C/EBP DNA-binding activity is upregulated by a glucocorticoid-dependent mechanism in septic muscle. American Journal of Physiology Regulatory Integrative and Comparative Physiology 282 R439-R444.

Rakugi H, Kamide K \& Ogihara T 2002 Vascular signaling pathways in the metabolic syndrome. Current Hypertension Reports 4 105-111.

Reynolds RM \& Walker BR 2003 Human insulin resistance: the role of glucocorticoids. Diabetes, Obesity and Metabolism 5 5-12.

Rosmond R 2003 Stress induced disturbances of the HPA axis: a pathway to Type 2 diabetes? Medical Science Monitor 9 RA35-RA39.

Sakurai T, Yanagisawa M, Inoue A, Ryan US, Kimura S, Mitsui Y, Goto K \& Masaki T 1991 cDNA cloning, sequence analysis and tissue distribution of rat preproendothelin-1 mRNA. Biochemical and Biophysical Research Communications 175 44-47.

Samec S, Seydoux J \& Dulloo AG 1999 Post-starvation gene expression of skeletal muscle uncoupling protein 2 and uncoupling protein 3 in response to dietary fat levels and fatty acid composition: a link with insulin resistance. Diabetes 48 436-441.

Santure M, Pitre M, Marette A, Deshaies Y, Lemieux C, Lariviere R, Nadeau A \& Bachelard H 2002 Induction of insulin resistance by high-sucrose feeding does not raise mean arterial blood pressure but impairs haemodynamic responses to insulin in rats. British Journal of Pharmacology 137 185-196.

Schimmer B \& Parker K 1996 Adrenocorticotrophic hormones; adrenocortical steroids and their synthetic analogs; inhibitors of synthesis and actions of adrenocortical hormones In Goodman and Gilman's the Pharmacological Basis of Therapeutics, pp 1459-1486. Eds J Hardman, L Limbird, B Molinoff, R Ruddon \& A Goodman-Gilman. New York: McGraw Hill.

Senn JJ, Klover PJ, Nowak IA \& Mooney RA 2002 Interleukin-6 induces cellular insulin resistance in hepatocytes. Diabetes $\mathbf{5 1}$ 3391-3399.

Senn JJ, Klover PJ, Nowak IA, Zimmers TA, Koniaris LG, Furlanetto RW \& Mooney RA 2003 Suppressor of cytokine signaling-3 (SOCS-3), a potential mediator of interleukin-6-dependent insulin resistance in hepatocytes. Journal of Biological Chemistry 278 13740-13746.

Seo J, Bakay M, Chen Y, Himler S, Shneiderman B \& Hoffman E 2004 Interactively optimizing signal/noise ratios in expression profiling: project-specific algorithm selection and detection $\mathrm{p}$ value weighting in affymetrix microarrays. Bioinformatics 20 2534-2544.

Sesti G 2000 Insulin receptor substrate polymorphisms and type 2 diabetes mellitus. Pharmacogenomics 1 343-357.

Shimano H 2002 Sterol regulatory element-binding protein family as global regulators of lipid synthetic genes in energy metabolism. Vitamins and Hormones 65 167-194.

Shirakami A, Toyonaga T, Tsuruzoe K, Shirotani T, Matsumoto K, Yoshizato K, Kawashima J, Hirashima Y, Miyamura N, Kahn CR et al. 2002 Heterozygous knockout of the IRS-1 gene in mice enhances obesity-linked insulin resistance: a possible model for the development of type 2 diabetes. Journal of Endocrinology $\mathbf{1 7 4}$ 309-319.

Singh Ahuja H, Liu S, Crombie DL, Boehm M, Leibowitz MD, Heyman RA, Depre C, Nagy L, Tontonoz P \& Davies PJ 2001 Differential effects of rexinoids and thiazolidinediones on metabolic gene expression in diabetic rodents. Molecular Pharmacology 59 765-773.

Sreenan S, Keck S, Fuller T, Cockburn B \& Burant CF 1999 Effects of troglitazone on substrate storage and utilization in insulin-resistant rats. American Journal of Physiology Endocrinology and Metabolism 276 E1119-E1129.

Strommer L, Abou El-Ella G, Kamel A, Marcus C, Hager P, Adrian TE \& Permert J 2001 Upregulation of uncoupling protein 
homologues in skeletal muscle but not adipose tissue in posttraumatic insulin resistance. Biochemical and Biophysical Research Communications 281 334-340.

Sugden MC \& Holness MJ 2002 Therapeutic potential of the mammalian pyruvate dehydrogenase kinases in the prevention of hyperglycaemia. Current Drug Targets - Immune Endocrine and Metabolic Disorders 2 151-165.

Sugden MC, Orfali KA \& Holness MJ 1995 The pyruvate dehydrogenase complex: nutrient control and the pathogenesis of insulin resistance. Journal of Nutrition 125 1746S-1752S.

Sun Y, Diaz-Arias AA \& Weber KT 1994 Angiotensin-converting enzyme, bradykinin, and angiotensin II receptor binding in rat skin, tendon, and heart valves: an in vitro, quantitative autoradiographic study. Journal of Laboratory and Clinical Medicine 123 372-377.

Sun YN, DuBois DC, Almon RR \& Jusko WJ 1998a Fourth-generation model for corticosteroid pharmacodynamics: a model for methylprednisolone effects on receptor/gene-mediated glucocorticoid receptor down-regulation and tyrosine aminotransferase induction in rat liver. Journal of Pharmacokinetics and Biopharmaceutics 26 289-317.

Sun YN, DuBois DC, Almon RR, Pyszczynski NA \& Jusko WJ $1998 b$ Dose-dependence and repeated-dose studies for receptor/gene-mediated pharmacodynamics of methylprednisolone on glucocorticoid receptor down-regulation and tyrosine aminotransferase induction in rat liver. Journal of Pharmacokinetics and Biopharmaceutics 26 619-648.

Sun YN, McKay LI, DuBois DC, Jusko WJ \& Almon RR 1999 Pharmacokinetic/pharmacodynamic models for corticosteroid receptor down-regulation and glutamine synthetase induction in rat skeletal muscle by a receptor/gene-mediated mechanism. Journal of Pharmacology and Experimental Therapeutics 288 720-728.
Thogersen AM, Jansson JH, Boman K, Nilsson TK, Weinehall L, Huhtasaari F \& Hallmans G 1998 High plasminogen activator inhibitor and tissue plasminogen activator levels in plasma precede a first acute myocardial infarction in both men and women: evidence for the fibrinolytic system as an independent primary risk factor. Circulation 98 2241-2247.

Tomono S, Ohyama Y \& Uchiyama T 2002 Insulin resistance induced by drugs, inflammation and stress. Nippon Rinsho - Japanese Journal of Clinical Medicine 60 632-636.

Tumor Analysis Best Practices Working Group 2004 Expression profiling-best practices for data generation and interpretation in clinical trials. Nature Reviews Genetics 5 229-237.

Turgeon B, Saba-El-Leil MK \& Meloche S 2000 Cloning and characterization of mouse extracellular-signal-regulated protein kinase 3 as a unique gene product of $100 \mathrm{kD}$ a. Biochemical Journal 346 169-175.

Weigle DS, Selfridge LE, Schwartz MW, Seeley RJ, Cummings DE, Havel PJ, Kuijper JL \& BeltrandelRio H 1998 Elevated free fatty acids induce uncoupling protein 3 expression in muscle: a potential explanation for the effect of fasting. Diabetes 47 298-302.

Zador IZ, Hsieh CC \& Papaconstantinou J 1998 Renal CCAAT/enhancer-binding proteins in experimental diabetes mellitus. Nephron 79 312-316.

Zierath JR \& Wallberg-Henriksson H 2002 From receptor to effector: insulin signal transduction in skeletal muscle from type II diabetic patients. Annals of the New York Academy of Sciences 967 120-134.

Received 20 September 2004

Accepted 14 October 2004

Made available online as an

Accepted Preprint 21 October 2004 